\title{
Hormone Receptor Expression and Clinicopathologic Features in Male and Female Breast Cancer
}

\author{
Fatemeh Homaei Shandiz ${ }^{1}$, Aliraz Tavassoli ${ }^{2}$, Nourieh Sharifi ${ }^{3}$, Sima Ardalan \\ Khales $^{4}$, Sima Kadkhodayan ${ }^{5}$, Sahar Ardalan Khales ${ }^{6 *}$
}

\begin{abstract}
Background: Male and female breast cancers were investigated for variation in the clinicopathologic characteristics and expression of steroid hormone receptors in the northeast of Iran. Materials and Methods: Tumor specimens of 17 males and 338 females with breast cancer were collected at the hospitals of Mashhad University of Medical Sciences. Immunohistochemical expression of hormone receptors and clinicopathologic features of breast cancer were compared between two groups. Results: The mean age in men was 15 years higher than women $(\mathbf{p = 0 . 0 0 0})$. Males and females were mainly in stage II and III respectively $(\mathrm{p}=0.007)$. Although more than $60 \%$ of male and female patients were grade II, the respective figures for grade I and III were $25 \%$ and $12.5 \%$ in men but $7.1 \%$ and $27.2 \%$ in women respectively $(p=0.025)$. ER was significantly more positive in men against women; $82.3 \%$ versus $53.4 \%(\mathrm{p}=\mathbf{0 . 0 1 6})$. The related measures for PR was $\mathbf{5 8 . 8 \%}$ and $\mathbf{5 0 . 3 \%}$, respectively $(\mathrm{p}=0.424)$. Males also showed significantly more ER expression than postmenopausal females; $82.3 \%$ versus 48.9\% $(\mathrm{p}=\mathbf{0 . 0 1 0})$. Conclusions: Breast cancer in males and females contrasted in age at diagnosis, histological type, stage, grade and ER expression which emphasize they are separate diseases with different behaviors.
\end{abstract}

Keywords: Male - female - breast carcinoma - steroid receptor - stage - Iran

Asian Pac J Cancer Prev, 16 (2), 471-474

\section{Introduction}

Breast cancer ranks among most common cancers in Iranian women comprising $24.4 \%$ of all female malignancies (Mousavi et al., 2009). Up to now some studies have been focused on its clinical and histological features as well immunohistochemical biomarkers in Iranian women (Homaei-Shandiz et al., 2006; MoradiMarjaneh et al., 2008). This disease has been well studied for hormone receptors and their clinical value in different regions. Females with estrogen receptor (ER) or progesterone receptor ( $\mathrm{PR}$ ) positive tumor are supposed to have better survival and response to estrogen antagonists (Grann et al., 2005; Moradi-Marjaneh et al., 2008). In contrast male breast cancer takes place at a much lower rate than females. In the United States breast carcinoma of males is accounted about $1 \%$ of all breast cancers and it has been estimated to diagnose 2,360 new cases of male breast cancer during 2014 (American Cancer Society, 2014).

However limited data are available concerning its epidemiology in Iran. Because of the rarity of male breast cancer, it has been the field of few investigations and limited funding opposed to female breast cancer. Breast cancer in males was formerly supposed to be more aggressive and mortal than in females (Ciatto et al., 1990). By collecting more data, it was shown that breast cancer in men and women are biologically similar (Vetto et al., 1999).

However some apparent differences have been appeared until now mainly in clinicopathologic characteristics (Giordano et al., 2004). The available findings of such investigations are not completely wellmatched. In addition, the heterogeneity of breast cancer has been leaded to various reports of biological and clinical characteristics in different races and ethnicities (Bowen et al., 2006). Therefore, further studies are obviously needed for better understanding of male breast cancer in different geographic locations. Up to now, no work has been carried out to describe the clinicophatolgic pattern and the status of molecular biomarkers in Iranian men with breast cancer. So this study aimed at investigation of male and female breast cancers for differences in the clinicopathologic features and expression of steroid hormone receptors in the northeast of Iran. 


\section{Materials and Methods}

\section{Patients}

Tumor specimens of 17 men and 338 women with breast cancer were collected at Ghaem Hospital of Mashhad University of Medical Sciences between October 2006 and January 2013. This hospital is known as the referral center for cancer patients from the northeast of Iran.

\section{Clinicopathologic parameters}

Grading was performed based on the Bloom Richardson system according to the tubule formation, nuclear pleomorphism and mitotic count.

Stages of the disease were compared with AJCC staging system 2006. Clinicopathological data was extracted from our hospital database. Tissue specimens were examined by an expert histopathologist.

\section{Immunohistochemical analysis}

The paraffin blocks of patients were immunohistochemically stained for ER(Estrogen receptor) and PR (progesterone receptor) markers using the peroxidase-antiperoxidase (PAP) method.After cutting the paraffin blocks into 3 to $5 \mu \mathrm{m}$ thick sections, they were put in room temperature for 24 hours. Subsequently immunohistochemistry staining were done applying monoclonal mouse anti-human progesterone receptor, clone PgR 636 and monoclonal mouse anti-human estrogen receptor, clone 1D5.

Normal breast tissue was used for positive control of ER and PR markers and for negative control; antibody was omitted from staining process. Specimens were considered to be positive if their proportion of tumoral cells with positive nuclear staining was $3 \%$ or more.
Statistical analysis

Immunohistochemical expression of hormone receptors and Clinicopathologic characteristics of breast cancer were compared between males and females. Data were analyzed by SPSS software (version 14) and a $\mathrm{p}$ value $\leq 0.05$ was considered to be significant. Chi-square and T-tests were adopted for comparing qualitative and quantitative variables, respectively.

\section{Ethical considerations}

Research was performed on the paraffin blocks of pathological samples. This study was approved by the ethics committee at university of Mashhad. Samples were coded with registry numbers and were anonymous. All patients' information was confidential.

\section{Results}

Clinical and histopatological characteristics of studied patients have been shown in Table 1 . The mean age in men and women was 62.98 and 48.05 years respectively that significantly were different $(\mathrm{p}=0.000)$. According to pathological reports, all males had infiltrating ductal carcinoma but significantly only $76.2 \%$ of females suffered from infiltrating ductal carcinoma $(\mathrm{p}=0.006)$. The most frequent stages in two groups of patients were II and III respectively ( $\mathrm{p}=0.007)$. We found that just $2(12.5 \%)$ men had larger than 5cm tumors. But $139(41.7 \%)$ women had the same size tumors $(\mathrm{p}=0.092)$. The mean number of positive axillary lymph nodes in males and females were 3.33 (ranging from 0 to 27 ) and 4.4 nodes (ranging from 0 to 27 ) respectively ( $\mathrm{p}=0.259$ ). Five $(29.4 \%)$ male and $154(46.1 \%)$ female patients had 4 or more positive axillary lymph nodes $(\mathrm{p}=0.069)$. As far as the tumor stage is concerned, only $1(7.7 \%)$ man and $5 \%$ of women had

Table 1. Clinical and Histopatological Characteristics of Male and Female Breast Cancers

\begin{tabular}{|c|c|c|c|c|}
\hline Factor & & $\begin{array}{c}\text { Female Breast Cancer } \\
n=338(95.2 \%)\end{array}$ & $\begin{array}{c}\text { Male Breast Cancer } \\
n=17(4.8 \%)\end{array}$ & $\mathrm{P}_{\text {value }}{ }^{1}$ \\
\hline$\overline{\text { Age (year) }}$ & $\begin{array}{l}\text { Mean } \\
\text { St. D. }{ }^{2} \\
\text { Range }\end{array}$ & $\begin{array}{r}48.05 \\
12.07 \\
21-92\end{array}$ & $\begin{array}{r}62.98 \\
12.54 \\
42-82\end{array}$ & 0.000 \\
\hline Stage & $\begin{array}{l}\text { I } \\
\text { II } \\
\text { III } \\
\text { IV } \\
\text { Unknown }\end{array}$ & $\begin{aligned} & 71(21.6 \%) \\
& 107(32.6 \%) \\
& 137(41.7 \%) \\
& 13(4.0 \%) \\
& 10\end{aligned}$ & $\begin{array}{c}3(18.7 \%) \\
9(56.2 \%) \\
3(18.7 \% \\
1(6.2 \%) \\
1\end{array}$ & 0.007 \\
\hline Size of breast mass $(\mathrm{cm})$ & $\begin{array}{l}\text { Mean } \\
\text { St. D. } \\
\text { Range }\end{array}$ & $\begin{array}{l}4.57 \\
2.42 \\
0.5-17\end{array}$ & $\begin{array}{l}2.68 \\
2.06 \\
7-J a n\end{array}$ & 0.030 \\
\hline Number of positive lymph node & $\begin{array}{l}\text { Mean } \\
\text { St. D. } \\
\text { Range }\end{array}$ & $\begin{array}{c}4.4 \\
4.74 \\
0-27\end{array}$ & $\begin{array}{r}3.33 \\
5.62 \\
0-27\end{array}$ & 0.259 \\
\hline Grading & $\begin{array}{l}\text { I } \\
\text { II } \\
\text { III } \\
\text { Unknown }\end{array}$ & $\begin{aligned} & 16(7.1 \%) \\
& 147(65.6 \%) \\
& 61(27.2 \%) \\
& 114\end{aligned}$ & $\begin{array}{l}2(25 \%) \\
5(62.5 \%) \\
1(12.5 \%) \\
9\end{array}$ & 0.025 \\
\hline
\end{tabular}

${ }^{* 1} \mathrm{P}$ values from chi - square or fisher's exact test $(\mathrm{p}>0.05=$ significant $),{ }^{2}$ Standard deviation 
Table 2. ER \& PR Status in Male and Female Breast Cancers

\begin{tabular}{lccc}
\hline & $\begin{array}{c}\text { Female breast cancer } \\
\text { Positive/total (\%) }\end{array}$ & $\begin{array}{c}\text { Male breast cancer } \\
\text { Positive/total (\%) }\end{array}$ & P value \\
\hline ER & $179 / 335(53.4 \%)$ & $14 / 17(82.3 \%)$ & 0.016 \\
PR & $168 / 334(50.3 \%)$ & $10 / 17(58.8 \%)$ & 0.424 \\
\hline
\end{tabular}

Table 3. ER \& PR status in Male and Post Menopausal Female Breast Cancer

\begin{tabular}{cccc}
\hline & $\begin{array}{c}\text { Post menopausal Female } \\
\text { Breast Cancer } \\
\text { Positive/Total (\%) }\end{array}$ & $\begin{array}{c}\text { Male Breast Cancer } \\
\text { Positive/Total } \\
(\%)\end{array}$ & P value \\
\hline ER & $46 / 94(48.9 \%)$ & $14 / 17(82.3 \%)$ & 0.010 \\
PR & $42 / 94(44.7 \%)$ & $10 / 17(58.8 \%)$ & 0.277 \\
\hline
\end{tabular}

metastasis of breast cancer. Breast cancer of both males and females were mainly grade II (more than $60 \%$ in both groups). However the respective figures for grade I and III were $25 \%$ and $12.5 \%$ in men but $7.1 \%$ and $27.2 \%$ in women respectively $(\mathrm{p}=0.025)$. ER was significantly positive in $14(82.3 \%)$ of men against $179(53.4 \%)$ of women $(\mathrm{p}=0.016)$. $\mathrm{PR}$ was positive in $10(58.8 \%)$ of male and $168(50.3 \%)$ of female cases $(\mathrm{p}=0.424)$ (Table 2$)$. After selection the postmenopausal women and comparison with male patients, males also showed significantly more ER expression than postmenopausal females; $82.3 \%$ versus 48.9\% ( $\mathrm{p}=0.010)$ (Table 3).

\section{Discussion}

In spite of uncommonness of male breast cancer, it has been considered as a cause of 430 deaths in the United States during 2014 which is more than mortality rate of several other cancers (American Cancer Society, 2014). However, limited researches have been conducted in this regard and our understanding of this disease is mainly based on experiences with female breast cancer. Despite the similarities of these cancers, some studies have reported their differences in the age at presentation, tumor histology, and the expression of molecular markers (Ruddy et al., 2013).

Considering the racial and ethnic effect on pathological and clinical aspects of breast cancer, understanding its variation among Iranian males and females will be valuable to optimize the approach to Iranian men suffered from breast cancer. The mean age at diagnosis of male breast cancer is around 63 years compared with nearly 59 years in women (Greif et al., 2012) In our study mean age at diagnosis in male cases was 63 years that is significantly 15 years older than our female patients; 5 years less than the other studies but similar to Avisar's report (2006); Although it has been demonstrated that breast cancer affects Iranian women at least one decade younger than their counterparts in developed countries (Mousavi et al., 2007). Men with breast cancer have a higher occurrence of ductal histology. Dauda et al.(2011) analysed 172 cases of breast cancers, the most common histopathological type of breast cancer found in that study was invasive ductal carcinoma no special type (NST) accounting for 78.8\% of cases (Dauda et al., 2011). Our data showed all male cases were ductal carcinoma while significantly $76.2 \%$ of female tumors were ductal carcinoma $(\mathrm{p}=0.006)$. Older survey has reported male breast cancer is diagnosed with more advanced stage than in women, with $42 \%$ of men presenting with stage III/IV disease (Micheli-Pellegrini, 1975; Zygogianni et al., 2012). However in our study, the most frequent stages in men and women were II and III respectively $(\mathrm{p}=0.007)$.

The etiology of male breast cancer has not been identified yet. However hormonal status is likely to be effective in the development of this disease. Like female breast cancer, lasting exposure to estrogen or to reduced androgen seems to increase the risk of male breast cancer. Men with Klinefelter's syndrome have a 20 to 50 times greater risk of breast cancer compared to men without this condition(Wisinski, 2010). Approximately 90\% of male breast cancers express the estrogen receptor (ER), and $81 \%$ express the progesterone receptor (PR) (Giordano et al., 2004). Cancers of the male breast are considerably more likely than of the females to express estrogen and progesterone receptors (Gomez-Raposo et al., 2010). Breast cancer of men is more similar to postmenopausal female breast cancer than premenopausal ones (Anderson et al., 2004). Of our male patients, $82.3 \%$ and $58.8 \%$ were ER and PR positive respectively which are less than other reports especially PR expression. But the expression of ER in men was significantly more than women group as well as postmenopausal cases. ER and PR have been measured in female breast cancer tissues for decades and it is necessary to make a decision for optimal treatment. Positive cases highly benefit hormonal therapy. But although male breast cancers are more positive for estrogen and/or progesterone receptors than female breast cancers, the effectiveness of hormonal therapy in men is still doubted because of the difference in hormonal atmosphere in men and women.

In conclusion, breast cancer in males and females contrasted in age at diagnosis, histological type, stage of disease, tumor grade and ER expression. So it becomes more clear that they are separate diseases with different behaviors, But obviously the characteristics of male breast cancer in Iran is not different from the Western countries, lack of adequate data on prognosis and treatment is still obvious and more researches are needed to be done on sufficiently large numbers.

\section{Acknowledgements}

This work was supported by grants from Research Council of Mashhad University of Medical Sciences (code number $=83228$ ). We would like to thank Mr. Afshari for his helpful guidance. We declare conflict of interest.

\section{References}

Anderson WF, Althuis MD, Brinton LA, Devesa SS (2004). Is male breast cancer similar or different than female breast cancer? Breast Cancer Res Treat, 83, 77-86.

Bowen RL, StebbingJ, Jones LJ (2006). A review of the ethnic differences in breast cancer. Pharmacogenomics, 7, 935-42.

Ciatto S, Iossa A, Bonardi R, Pacini P. (1990). Male breast 
Fatemeh Homaei-Shandiz et al

carcinoma: review of a multicenter series of 150 cases. Coordinating Center and Writing Committee of FONCAM (National Task Force for Breast Cancer), Italy. Tumori, 76, 555-8.

Dauda AM, Misauno MA, Ojo EO. (2011). Histopathological types of breast cancer in Gombe, North Eastern Nigeria: a seven-year review. Afr J Reprod Health, 15, 109-11.

Giordano SH, Cohen DS, Buzdar AU, Perkins G, Hortobagyi, GN (2004). Breast carcinoma in men: a population-based study. Cancer, 101, 51-7.

Gomez-Raposo C,Zambrana Tevar F, Sereno Moyano M (2010). Male breast cancer. Cancer Treat Reviews, 36, 451-75.

Grann VR, Troxel AB, Zojwalla NJ, et al (2005). Hormone receptor status and survival in a population-based cohort of patients with breast carcinoma. Cancer, 103, 2241-51.

Greif JM, Pezzi CM, Klimberg VS, Bailey L, Zuraek M. (2012). Gender differences in breast cancer: analysis of 13,000 breast cancers in men from the National Cancer Data Base. Ann Surg Oncol, 19, 3199-204.

Homaei-Shandiz F, Ghavam-Nassiri MR, Sharifi N, et al (2006). Evaluation of the relationship between human epidermal growth factor receptor-2/neu (c-erbB-2) amplification and pathologic grading in patients with breast cancer. Saudi Med J, 27, 1810-4.

Micheli-Pellegrini V. (1975). Letter: More on lid-loading in the management of lagophthalmos. Plast Reconstr Surg, 55, 482 .

Moradi-Marjaneh M, Homaei-Shandiz F, Shamsian SAA, Eftekhar-Zadeh Mashhadi I (2008). Correlation of HER2/ neu over expression, 553 protein accumulation and steroid receptor status with tumor characteristics: an Iranian study of breast cancer patients. Iran J Public Health, 37, 19-28.

Mousavi SM, Gouya MM, Ramazani R, et al (2009). Cancer incidence and mortality in Iran. Ann Oncol, 20, 556-63.

Mousavi SM, MontazeriA, Mohagheghi MA, et al (2007). Breast cancer in Iran: an epidemiological review. Breast $J, \mathbf{1 3}, 383-91$.

Ruddy KJ, Winer EP. (2013). Male breast cancer: risk factors, biology, diagnosis, treatment, and survivorship. Ann Oncol, 24, 1434-43.

Vetto J, Jun SY, Paduch D, et al (1999). Stages at presentation, prognostic factors, and outcome of breast cancer in males. American J Surgery, 177, 379-83.

Wisinski KB, GW (2010). Male breast cancer . In W. and W. Harris JR, Lippman ME, Morrow M, Osborne CK Diseases of the Breast, 34thrd edition (4th ed.,pp. 775-780). Philadelphia.

Zygogianni AG, Kyrgias G, Gennatas C, et al (2012). Male breast carcinoma: epidemiology, risk factors and current therapeutic approaches. Asian Pac J Cancer Prev, 13, 15-9. 